9 Correspondence: Shichang Kang (shichang.kang@lzb.ac.cn)

10 Abstract. The retreat of sea ice is very significant in the Arctic under global warming.

11 It is projected to continue and have great impacts on navigation. In this investigation,

\section{Perspectives on future sea ice and navigability in the Arctic}

$$
\text { Jinlei Chen }{ }^{1} \text {, Shichang Kang }{ }^{1,2} \text {, Wentao } \mathrm{Du}^{1} \text {, Junming Guo }{ }^{1} \text {, Min } \mathrm{Xu}^{1} \text {, Xinyue }
$$

$$
\text { Zhong }^{3} \text {, Wei Zhang }{ }^{1} \text {, Jizu Chen }{ }^{1}
$$

${ }^{1}$ State Key Laboratory of Cryospheric Science, Northwest Institute of Eco-Environment and Resources, Chinese Academy of Sciences, Lanzhou 730000, China

${ }^{2}$ CAS Centre for Excellence in Tibetan Plateau Earth Sciences, Beijing 100101, China

${ }^{3}$ Key Laboratory of Remote Sensing of Gansu Province, Northwest Institute of Eco-Environment and Resources, Chinese Academy of Sciences, Lanzhou 730000, China decadal changes in sea ice parameters were evaluated by multimodel from the Coupled Model Intercomparison Project Phase 6, and Arctic navigability was assessed under two shared socioeconomic pathways (SSPs) and two vessel classes within the Arctic transportation accessibility model. The sea ice extent is expected to decrease along the SSP5-8.5 scenario with a high possibility under current emissions and climate change. The decadal decreasing rate will increase in March but decrease in September until 2060 when the oldest ice completely disappears and sea ice changes reach an irreversible tipping point. The sea ice thickness will decrease and transit in parts of the Arctic and will decline overall by $-0.22 \mathrm{~m}$ per decade after September 2060 . Both the sea ice concentration and volume will thoroughly decline with decreasing decadal rates, while the decrease in volume will be higher in March than in September. Open water 
ships will be able to cross the Northeast Passage and Northwest Passage in AugustOctober 2045-2055, with a maximum navigable area in September. The opportunistic crossing time for polar class 6 (PC6) ships will advance to October-December in 20212030, while the maximum navigable area will be seen in October. In addition, the Central Passage will also open for PC6 ships during September-October in 2021-2030.

\section{Introduction}

The Arctic has experienced significant warming since the 1970s (Connolly et al., 2017). Along with the increasing surface air temperature, the Arctic communities have experienced unprecedented changes, such as reductions in sea ice extent and thickness, loss of the Greenland ice sheet, a decrease in snow coverage, and thawing of permafrost (Biskaborn et al., 2019; Box et al., 2019; Brown et al., 2017; Loomis et al., 2019). The sea ice extent has declined at a rate of approximately $3.8 \%$ per decade. In comparison, perennial ice has a higher proportion of loss, at approximately $11.5 \%$ per decade from 1979-2012 (Comiso and Hall, 2014). The average ice thickness near the end of the melt season decreased by $2.0 \mathrm{~m}$ or $66 \%$ between the pre-1990 submarine period (1958-1976) and the CryoSat-2 period (2011-2018) (Kwok, 2018). Continued declines in sea ice are projected by the Coupled Model Intercomparison Project Phase 5 in the Arctic through the end of the century (Meredith et al., 2019), though some significant timing differences have been predicted (Stephenson et al., 2013).

Sea ice insulates thermal transport between the ocean and atmosphere by reflecting a high proportion of incoming solar radiation back to space (Screen and Simmonds, 2010). With retreating sea ice, thermohaline circulation has changed (Jourdain et al., 
2017), and global warming has intensified (Abe et al., 2016). However, the shrinking and thinning of sea ice leads to prolonged open water conditions for the Arctic passages (Barnhart et al., 2015). The Northeast Passage (NEP) extends along the northern coast of Eurasia from Iceland to the Bering Strait and shortens the transit distance from northwest North America and northeast Asia to northern Europe by approximately $15 \%-50 \%$ relative to the southern routes through the Panama Canal and Suez Canal (Buixadé Farré et al., 2014). It is navigable for approximately a month and half per year for ice-strengthened ships at the end of summer (Khon et al., 2010). The day at which open water (OW) ships can cross the NEP has reached 297 \pm 4 (October 24th) since 2010. However, navigability is still affected by the ice regime around the Severnaya Zemlya Islands, the Novosibirsk Islands, and the East Siberian Sea (Chen et al., 2019). The Northwest Passage (NWP) follows the northern coast of North America and crosses the Canadian Arctic archipelago. Compared to the traditional Panama Canal route from Western Europe to the Far East, the NWP shortens the transit distance by $9000 \mathrm{~km}$ (Howell and Yackel, 2004). The shortest navigable period reached 69 days during the period from 2006-2015 (Liu et al., 2017), and the first time the NWP was completely ice free was in September 2007 (Cressey, 2007).

For the development of socioeconomics and marine transportation, future projections of ice conditions and Arctic passages are very important, and climatic changes should be taken into account (Gascard et al., 2017). Climate models are effective and reliable for producing present and future spatial and temporal distributions of Arctic sea ice (Parkinson et al., 2006; Stroeve et al., 2014). Smith and Stephenson 
67 (2013) investigated the potential of Arctic passages under representative concentration pathways (RCPs) 4.5 and 8.5 and found that OW ships and Polar Class 6 (PC6) ships will be able to cross the NEP and NWP in September by mid-century, respectively. The areas of the Arctic that will be accessible to PC3, PC6, and OW ships are expected to rise to $95 \%, 78 \%$, and $49 \%$, respectively, of the circumpolar boundary area delineated by the International Maritime Organization guidelines by the late 21st century (Stephenson et al., 2013). Melia et al. (2017) suggested that the Arctic passages from Europe to Asia will be 10 days faster than conventional routes by mid-century and 13 days faster by the later part of the century. Recent research has shown that the NEP might become accessible earlier for OW ships in September 2021-2025, and the navigable window may extend to August-October during 2026-2050 under shared socioeconomic pathways (SSPs) 2-4.5 (Chen et al., 2020). However, it is deficient to evaluate sea ice conditions and Arctic navigability by a single climate model, even with a high resolution.

This prospective study was designed to obtain further insight into the future changes in sea ice in the Arctic and the navigability of the Arctic during this century with ensemble up-to-date climate models in the Coupled Model Intercomparison Project Phase 6 (CMIP6). The models were filtered by comparing historical simulations and observations of sea ice extent, and the possible shared socioeconomic pathways were investigated with the averages of multiple models. The distributions of the linear trends of sea ice extent, concentration, and thickness were explored in three stages (2021-2040, 2041-2060, and 2061-2100). In addition, the changes in sea ice volume 
and age were analyzed. The accessibility of the Arctic and the navigable area were evaluated with the Arctic Transportation Accessibility Model (ATAM) developed by the Arctic Ice Regime Shipping System (AIRSS) for OW ships and PC6 ships under SSP2-4.5 and SSP5-8.5 in 2021-2030 and 2045-2055, respectively.

\section{Methods}

\subsection{Data and Model Selection}

The new scenario framework, SSP, in CMIP6 was designed to carry out research on climate change impacts and adaptions by combining pathways of future radiative forcing and climate changes with socioeconomic developments (O’Neill et al., 2014). Compared with CMIP5 models, the CMIP6 multimodel ensemble mean provides a more realistic estimate of the Arctic sea ice extent (SIMIP Community, 2020), but the biases of the models are still large (Shu et al., 2020). This paper selected models by comparing the historical trends of sea ice extent with observations from the National Snow \& Ice Data Center during 1979-2012 with a five-point moving average (Figure 1). The excellent models are those with a correlation coefficient greater than $0.8(0.7$ for March). As shown in Figure 1, 14 historical models were evaluated in both March and September. The models that passed the test were CESM2, MPI-ESM1-2-HR, MPIESM1-2-LR, NorESM2-LM, NorESM2-MM, ACCESS-ESM1-5, AWI-CM-1-1-MR, and AWI-ESM-1-1-LR in September and CESM2, MPI-ESM1-2-LR, ACCESSESM1-5, AWI-CM-1-1-MR, INM-CM5-0, MPI-ESM-1-2-HAM, and AWI-ESM-1-1LR in March. The mean of the excellent models corresponds well with the observations, and the correlation coefficients are 0.884 and 0.817 in September and March, 

$1^{\circ} \times 1^{\circ}$ by bilinear interpolation.
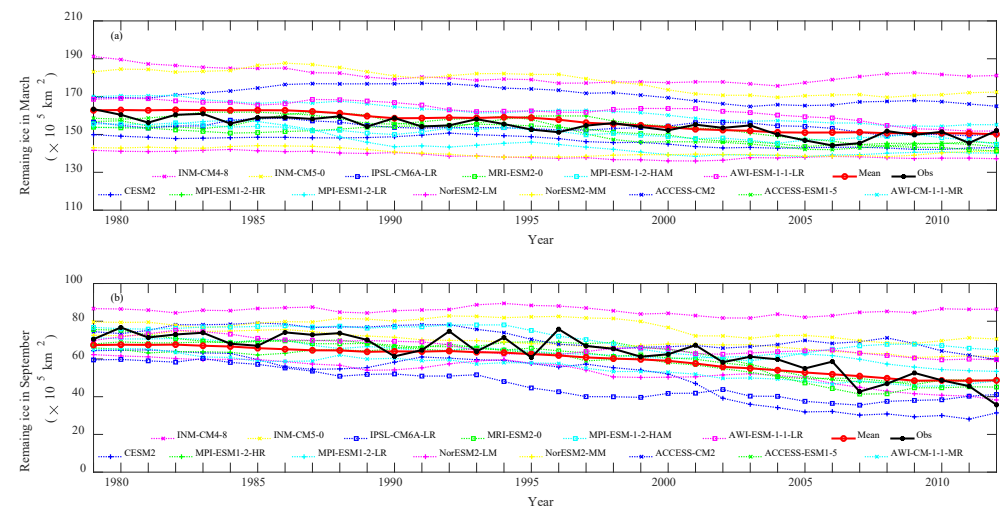

117

Figure. 1. Five-point moving average of sea ice extents in March and September during

1979-2012.

\subsection{Accessibility Evaluation}

Safety and pollution are two opposing factors that are considered when making regulatory transport standards. The AIRSS was designed to minimize the risk of pollution in the Arctic due to damage to vessels by ice (Transport Canada, 1998). The ATAM, developed by the AIRSS, is commonly used to quantify temporal and spatial accessibilities in the Arctic; in the ATAM, the ability of a ship to enter ice-covered water can be represented by the ice number (IN):

$$
I N=\left(\mathrm{C}_{a} * \mathrm{IM}_{a}\right)+\left(\mathrm{C}_{b} * \mathrm{IM}_{b}\right)+\ldots+\left(\mathrm{C}_{n} * \mathrm{IM}_{n}\right)
$$


128 where $\mathrm{IM}_{a}, \mathrm{IM}_{b}$, and $\mathrm{IM}_{n}$ are the ice multipliers of ice types $\mathrm{a}, \mathrm{b}$, and $\mathrm{n}$,

129 respectively. $\mathrm{C}_{a}, \mathrm{C}_{b}$, and $\mathrm{C}_{n}$ are the sea ice concentrations. The ice multipliers

130 indicate the severity of each ice type for the given vessel and range from -4 to 2 . Positive

131 IM and IN values represent less risk to the given vessel and a safe region for navigation,

132 respectively. The vessel class is a characteristic of a ship that reflects its structural

133 strength, displacement, and power to break ice. PC6 ships and OW ships are vessels

134 that are moderately ice-strengthened and not ice-strengthened, respectively (IMO,

135 2002). In this paper, the navigability of the Arctic for each of these two kinds of ships

136 was investigated under SSP2-4.5 and SSP5-8.5. The IMs for two kinds of ships are as

137 follows:

$$
\begin{aligned}
& I M_{O W}= 2, \text { if } S I T=0 \mathrm{~cm}, \\
& 1, \text { if } 0 \mathrm{~cm}<S I T<15 \mathrm{~cm}, \\
&-1 \text {, if } 15 \mathrm{~cm}<=S I T<70 \mathrm{~cm}, \\
&- \text {, if } 70 \mathrm{~cm}<=S I T<120 \mathrm{~cm}, \\
&-3 \text {, if } 120 \mathrm{~cm}<=S I T<151 \mathrm{~cm}, \\
&- 4 \text {, if } S I T>=151 \mathrm{~cm} \\
& I M_{P C 6}= 2 \text {, if } 0 \mathrm{~cm}<=S I T<70 \mathrm{~cm}, \\
& 1 \text {, if } 70 \mathrm{~cm}<=S I T<120 \mathrm{~cm}, \\
&-1, \text { if } 120 \mathrm{~cm}<=S I T<151 \mathrm{~cm}, \\
&-3, \text { if } 151 \mathrm{~cm}<=S I T<189 \mathrm{~cm}, \\
&-4 \text {, if } S I T>=189 \mathrm{~cm}
\end{aligned}
$$

\section{$141 \quad 3$ Results}

\section{$142 \quad 3.1$ Future Changes of Sea Ice Area and Extent}

The extent and area are the most reliable products of sea ice that can be obtained

144 from satellite retrievals (Comiso, 2012; Notz, 2014). Therefore, the remaining sea ice was taken as an indicator to evaluate the studied models and future scenarios. As shown 
146 in Figure 2, the observation trends were obtained with least square regressions of

147 historical ensemble averages from 1979-2019, in which the sea ice might completely

148 disappear in September after 2073. In addition to the classical pathways, such as SSP1-

149 2.6, SSP2-4.5, and SSP5-8.5, CMIP6 provides a variety of new selections. However,

150 SSP1-1.9, SSP4-3.4, and SSP4-6.0 were not discussed in the multiscenario evaluations

151 of the newer models. According to historical development and future scenarios, sea ice

152 will retreat in the future with a more significant decreasing trend in September. The

153 difference between the SSPs and observation trends is greater in March than in

154 September, while both March and September reflect large dispersions among pathways

155 after 2050. Compared with the other scenarios, SSP5-8.5 has the greatest correlation

156 coefficients, at 0.784 and 0.712 in September and March, respectively, with the

157 observation trend; SSP2-4.5 comes second. This suggests that the worst scenario for

158 Arctic sea ice in the future might occur under the current emission and climate change trends. The Arctic is regarded as "ice-free" when the sea ice area is less than one million square kilometers (Lenton et al., 2019). This is expected to occur in September 2060 

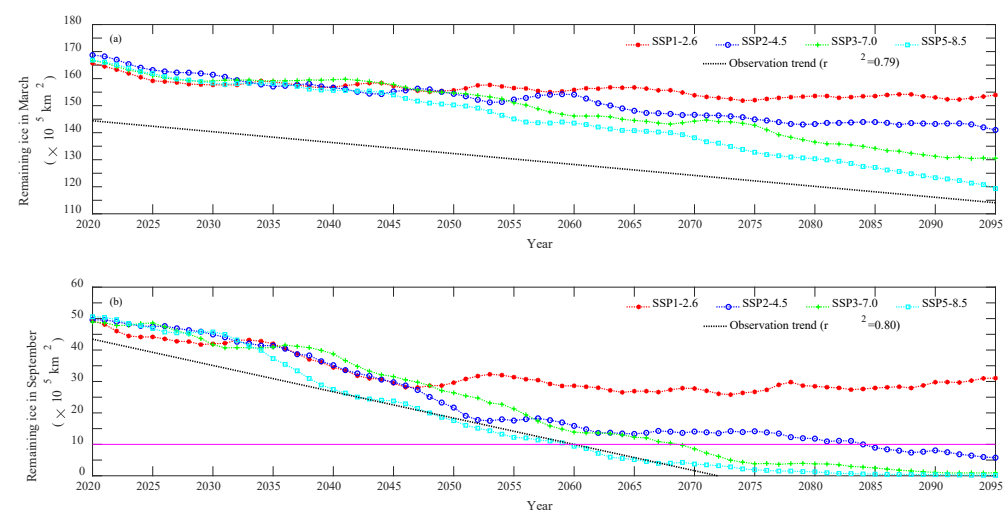

Figure. 2. Remaining sea ice under multiple scenarios and observation trends in the future.

"Ice-free" conditions can be considered a tipping point of climate change that has significant irreversible effects (Lenton et al., 2019). Three time periods were extracted and the expected changes in sea ice extent were calculated for each period, as shown in Figure 3. Decadal linear trends and probability distributions with an interval of 0.4 were calculated to evaluate the decline in sea ice and the differences among models. The linear sea ice trends are predicted to be less than zero in both March and September in 2021-2100, and the retreat will be more remarkable in September before 2060, especially during 2021-2040, after which the decline is mainly expected in March because the extent might be close to "ice-free" in September. The dispersion of the SSPs will increase in March over time, as will the absolute decadal trends of SSP3-7.0 and SSP5-8.5. However, the dispersion is aggregated in September, and the decadal variability in the SSPs, especially in SSP2-4.5 and SSP5-8.5, has a decreasing trend. The multimodel simulations mainly range from -0.8 to 0 million $\mathrm{km}^{2}$ per decade in March, in which the distributions of SSP5-8.5 are chiefly $[-0.4,0),[-0.8,-0.4)$, and [$0.8,-0.4)$ million $\mathrm{km}^{2}$ per decade during 2021-2040, 2041-2060, and 2061-2100, 
respectively. A relatively even distribution is shown in September before mid-century,

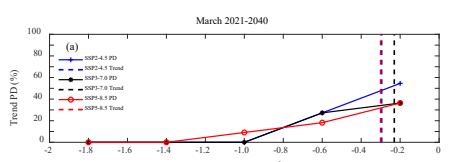

$\underset{\substack{\text { SIE trend (million } \mathrm{km} \\ \text { March } 2041-2060)}}{2}$

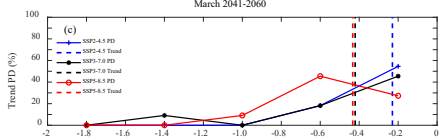

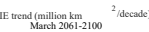

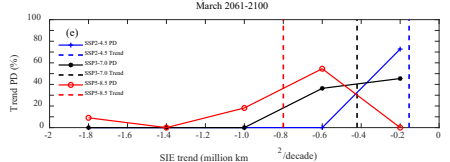

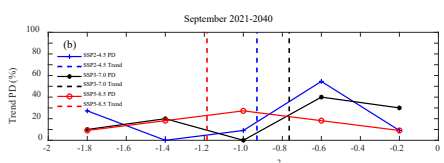

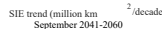

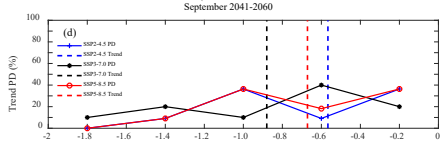

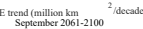

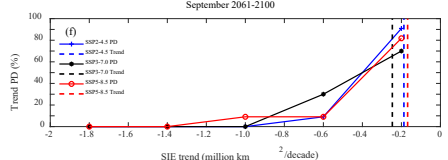

184

185

186

187

Figure. 3. Future linear trends and probability distributions (PD) of the Arctic sea ice extent (SIE) in March and September.

\subsection{Future Changes of Other Sea Ice Parameters}

In addition to the extent and area of sea ice, the thickness, concentration, volume, and age are also important indicators of future changes in sea ice. Figures 4 and 5 show the linear trends of sea ice thickness and concentration and changes in sea ice volume and age, respectively, under SSP5-8.5 in 2021-2100. Ice thickness has a negative trend within the Arctic Archipelago, coastal waters, and in the sector to the north of the Arctic Archipelago and Greenland in September, while the other regions will experience slight increases in sea ice thickness in the next 20 years. This trend is reversed in the Arctic Ocean, and the decreasing area near the shore will extend to the north in 2041-2060, after which the thickness of almost all of the sea ice will be reduced with an average 
197 trend of $-0.22 \mathrm{~m}$ per decade in the Arctic. The sea ice concentration will decrease 198 throughout the rest of this century. The area to the north of the Arctic Archipelago and 199 Greenland as well as the Arctic Basin will experience significant changes in September 2021-2040. The sea ice extents in these areas will shrink, and the decadal linear rates will decrease until the second half of the century, when the decreasing rates will be even and small in the Arctic. The average decadal change rates of sea ice concentration are predicted to be $-12.39 \%,-6.26 \%$, and $-0.81 \%$ in the three stages of $2021-2040$, 2041-2060, and 2061-2100, respectively. The sea ice volume will decrease in both March and September from 2021-2100. The decreasing rate is higher in March, while sea ice might completely disappear in September before 2090. Ice age is also a key descriptor of the state of sea ice cover. Compared to younger ice, older ice tends to be thicker and more resilient to changes in atmospheric and oceanic forcing (RichterMenge et al., 2019). The oldest ice ( $>4$ years old) makes up just a small fraction of the total sea ice in March currently and might eventually disappear around mid-century. With the degeneration of older ice, the extent of younger ice will increase in a given period of time, such as 3-4-year-old ice in the next 10 years, 2-3-year-old ice before 2035, and 1-2-year-old ice before 2050, after which multiyear ice will degrade into younger ice. First-year ice dominates the sea ice cover in the both present and future. First-year ice will increase mainly before 2060 and remain stable until 2090, after which it will start to decrease due to the lack of supplementation from degraded older ice. 
https://doi.org/10.5194/tc-2021-35

Preprint. Discussion started: 1 February 2021

(c) Author(s) 2021. CC BY 4.0 License.
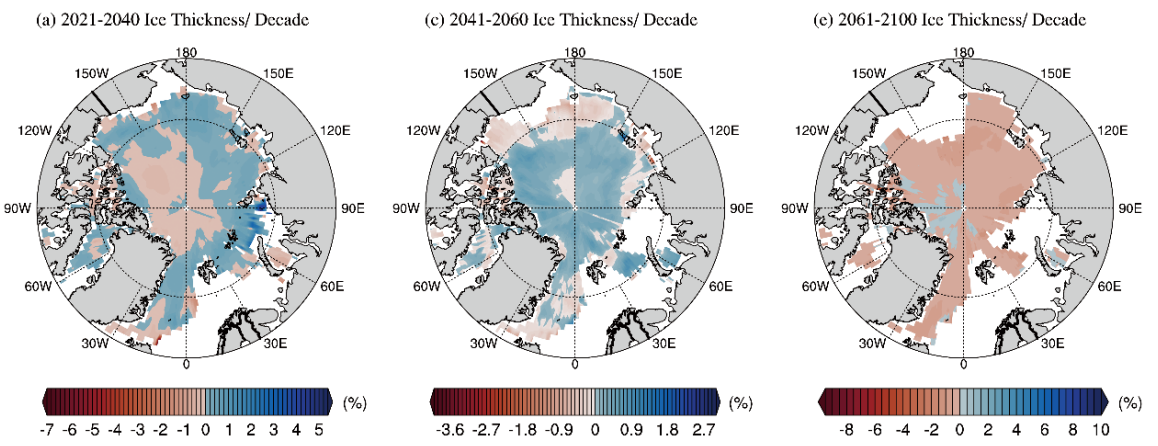

(b) 2021-2040 Ice Concentration/ Decade

(d) 2041-2060 Ice Concentration/ Decade

(f) 2061-2100 Ice Concentration/ Decade
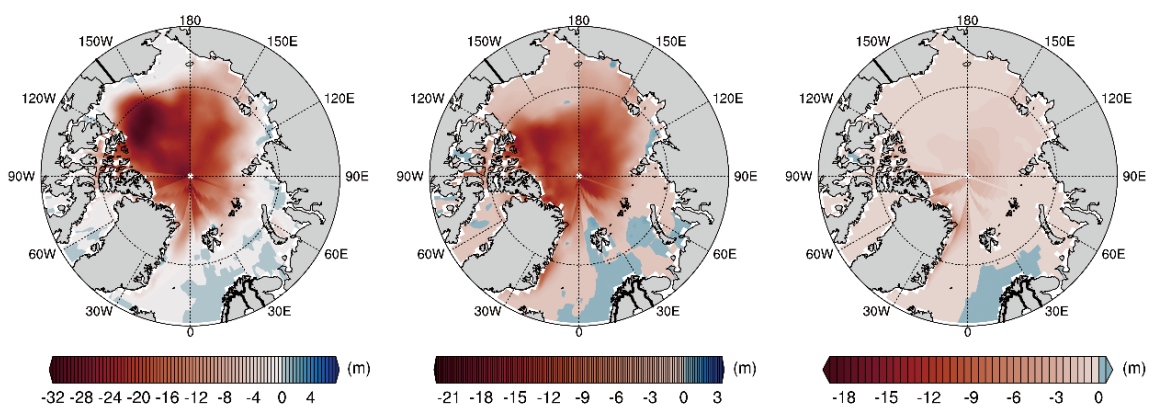

Figure. 4. Linear trends of ice thickness and concentration under SSP5-8.5 in September.
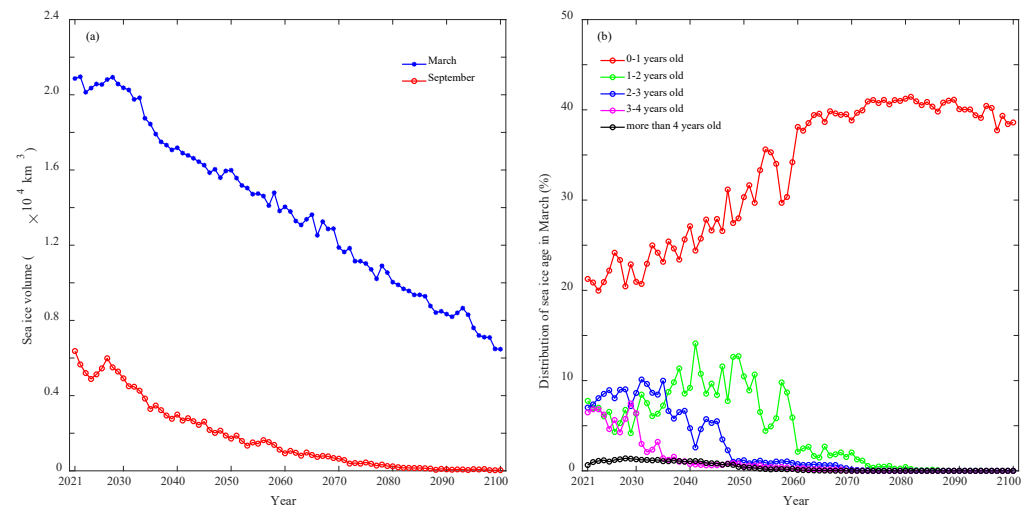

Figure. 5. Changes in sea ice volume and age under SSP5-8.5.

\subsection{Future Changes in Arctic Navigability}

With retreating sea ice, the possibility of navigation is rising in the Arctic. The number of vessels passing through the Arctic is increasing year by year, but OW ships usually need the guidance of icebreakers, which increases transportation costs. The 
225 opening of Arctic passages for OW ships is profitable for ocean shipping companies.

226 The most likely navigable window is in September. Figure 6 shows Arctic accessibility

227 for OW ships under SSP5-8.5 in September. The probability of crossing the NEP and

228 NWP is low in the next 10 years. The impassable areas of the NEP are mainly in the

229 East Siberian Sea and northwestern Laptev Sea, but nearshore waters might be

230 navigable for vessels with shallow drafts. Fortunately, the crucial straits, such as the

231 Shokalskiy Strait, Vilkitskty Strait, Sannikov Strait, and Dmitrii Laptev Strait, will be accessible for OW ships. The NWP is impassable in the sectors west of Banks Island and Queen Elizabeth Island, as well as the M'Clure Strait, Viscount-Melville Sound, in the Arctic marine shipping assessment report (AMSA, 2009) are under restrictions

(a) 2021-2030
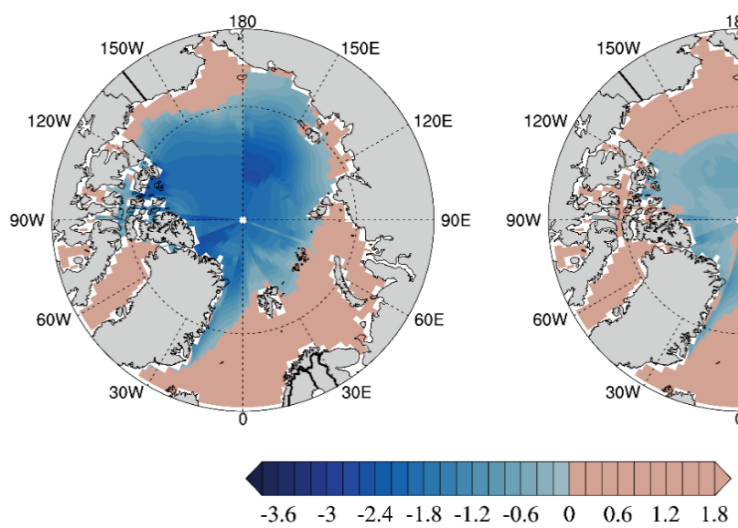

(b) 2045-2055

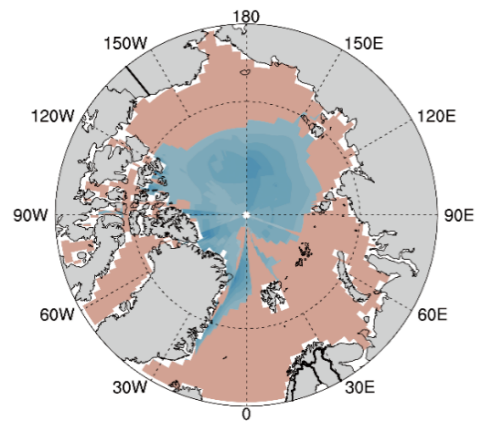

Figure. 6. Arctic navigability for OW ships under SSP5-8.5 in September.

The opening of the Arctic passages mainly depends on the connectivity among 
241 grids, during which the potential of individual units, which might connect with other

242 units in the next period, is usually ignored. The overall navigable potential in a region can be measured by the percentage of accessible grids relative to the total number of grids. Figure 7 displays the Arctic navigable percentage for two kinds of ships under SSP2-4.5 and SSP5-8.5 in 2021-2030 and 2045-2055. The totally navigable area for OW ships is shown as a unimodal curve in both stages, with a peak in September and a valley in April and March. An irregular curve is observed for PC6 ships, with a minimum value in June. The maximum values are shown in October 2021-2030, while the values range in November and December in the mid-century period. Actually, the Arctic will be navigable for PC6 ships from October to December. It is very strange that an abnormal decrease occurs in September in both the 2021-2030 and 2045-2055 periods. The navigable area within every 5 degrees of latitude from $65^{\circ} \mathrm{N}$ to $90^{\circ} \mathrm{N}$ is plotted in Figure 8 for further studies. This figure indicates that the abnormal point results from the observed decrease within the region of $85^{\circ} \mathrm{N}-90^{\circ} \mathrm{N}$, but the reason for this decrease is hard to explain. The navigable area is mainly concentrated in $65^{\circ} \mathrm{N}-$ $75^{\circ} \mathrm{N}$ for $\mathrm{OW}$ ships in the next 10 years and will extend to $80^{\circ} \mathrm{N}$ in the mid-century period. The central passage might be accessible for PC6 ships in September and October, and the open window is expected to be from October to January in 2045-2055. The routes of the NEP and NWP are mainly distributed in $70^{\circ} \mathrm{N}-75^{\circ} \mathrm{N}$. The possibility of OW ships crossing the two passages is low until August-October 2045-2055, while it is high for PC6 ships during October-December 2021-2030, and the open window is expected to extend to August-January in 2045-2055. 

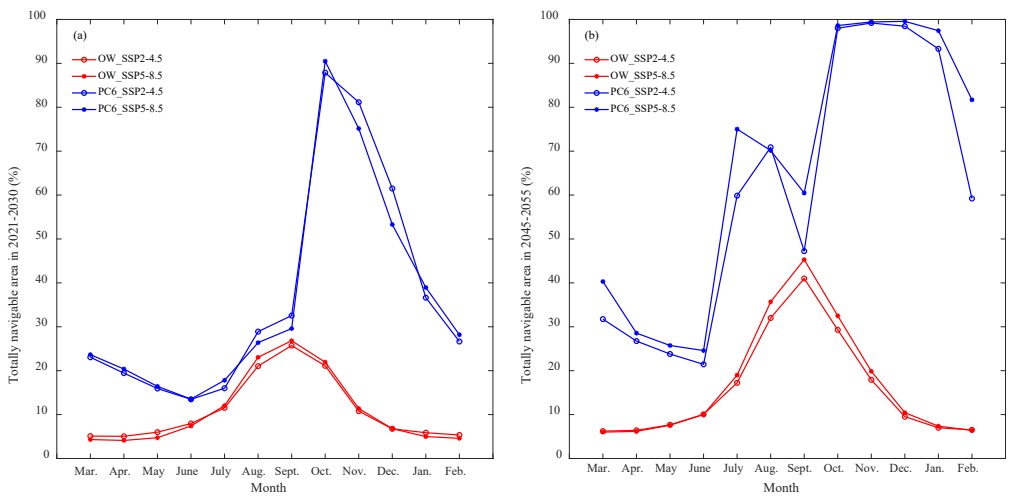

Figure. 7. Total navigable area for OW ships and PC6 ships under SSP2-4.5 and SSP5-8.5.
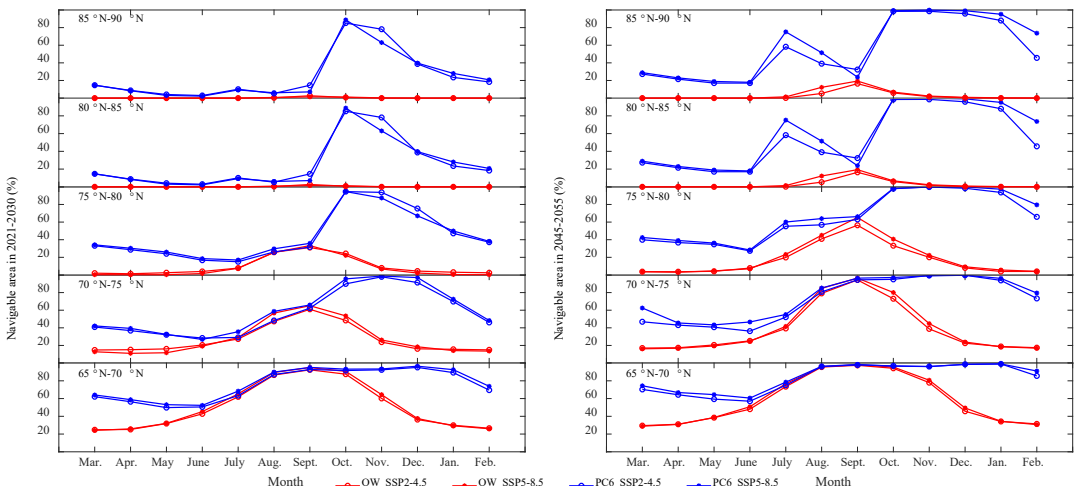

Figure. 8. Navigable area for OW ships and PC6 ships under SSP2-4.5 and SSP5-8.5 at different latitudes.

\section{Conclusions}

The Arctic warming rate is more than double the global average warming rate, and this warming has caused great impacts on the Arctic and globe (Cohen et al., 2020). This paper investigated the future changes in sea ice and the navigability of passages in the Arctic under two kinds of shared socioeconomic pathways. It provides a vision of the Earth's future and has great significance for navigation planning. The following results were found.

(1) Changes in sea ice are expected to occur along SSP5-8.5 with a higher possibility 
under the current trend. "Ice-free" regions might appear in September 2060, and sea ice is expected to completely disappear by the end of the century.

(2) Retreating sea ice is more significant in September before 2060, after which the decline is mainly shown in March. The decadal sea ice extent will increase under SSP5-8.5 in March but decrease in September.

281

(3) The decrease in sea ice thickness will transit from the Arctic Ocean north of the Arctic Archipelago and Greenland to the seas along Russia and North America and will totally decline with an average decadal trend of $-0.22 \mathrm{~m}$ in September after 2060. The sea ice concentration will thoroughly decline with decreasing decadal rates.

(4) The sea ice volume will decrease with a higher decadal rate in March than in September. The oldest ice might eventually disappear around the mid-century period. First-year ice will dominate the sea ice cover and will increase mainly before 2060 and remain stable until 2090, after which it will start to decrease.

(5) The probability of OW ships crossing the NEP and NWP is low in 2021-2030, while it is high in August-October 2045-2055, with maximum and minimum navigable areas in September and March, respectively.

(6) The passages along the coast and crossing the Arctic might open for PC6 ships during October-December and September-October 2021-2030, respectively, with a maximum navigable area in October. The open windows are expected to extend to August-January and October-January in 2045-2055, respectively, and the maximum navigable areas are expected between November and December. 
The navigable window for OW ships and PC6 ships along the NEP were investigated in our previous work (Chen et al., 2020), but it is deficient to evaluate Arctic navigability by a single climate model, even with a high resolution. This study serves as a reference for future changes in sea ice and navigability in the Arctic, including NEP, NWP, and Central Passage. However, the uncertainty of the models might have affected the results and their reliability in this research. Approximated physical processes and unreal parameters in models are inevitable problems in the geosciences. Differences still exist even though the models were filtered by comparing the historical simulations with observed sea ice extents. The predicted abnormal decrease in navigable area at high latitudes $\left(80^{\circ} \mathrm{N}-90^{\circ} \mathrm{N}\right)$ in September might be an example of this uncertainty. This prediction is against conventional wisdom, but it could also be true. The uncertainty of models is increasing in future prospective research.

Data Availability. All the data used in this paper are available online. The simulations

314

Author contributions. JLC and SK developed the concept, and investigated the methods of this paper. JLC and WD analyzed the data and wrote the original draft. JG, MX, XZ, 
$\mathrm{WZ}$ and $\mathrm{JZC}$ reviewed and edited the manuscript.

321

322

323

324

325

326

327

Competing interests. The authors declare that they have no conflict of interest.

Acknowledgements Thanks for the data from CMIP6 and NSIDC. Our cordial gratitude should be extended to anonymous reviewers and the Editors for their professional and pertinent comments on this manuscript.

Financial support. This work was financially supported by the National Natural Science Foundation of China (42005075 and 41721091), the Frontier Science Key Project of CAS (QYZDY-SSW-DQC021), the State Key Laboratory of Cryospheric Science (SKLCS-ZZ-2021), and Foundation for Excellent Youth Scholars of “Northwest Institute of Eco-Environment and Resources”, CAS (FEYS2019020).

\section{References}

Abe, M., Nozawa, T., Ogura, T., \& Takata, K.: Effect of retreating sea ice on Arctic cloud cover in simulated recent global warming, Atmos. Chem. Phy s., 16, 14343-14356, https://doi.org/10.5194/acp-16-14343-2016, 2016.

AMSA: Arctic marine shipping assessment 2009 report. Arctic Council, 2009.

Barnhart, K. R., Miller, C. R., Overeem, I., and Kay, J. E.: Mapping the future expansion of Arctic open water, Nat. Clim. Change, 6, 280-285, https://doi.o rg/10.1038/nclimate2848, 2015.

Biskaborn, B. K., Smith, S. L., Noetzli, J., Matthes, H., Vieira, G., Streletskiy, D. A.: Permafrost is warming at a global scale, Nat. Commun., 10, https:// 
doi.org/10.1038/s41467-018-08240-4, 2019.

Box, J. E., Colgan, W. T., Christensen, T. R., Schmidt, N. M., Lund, M., Par mentier, F.-J. W.: Key indicators of Arctic climate change: 1971-2017, En viron. Res. Lett., 14, 045010, https://doi.org/10.1088/1748-9326/aafc1b, 201 9.

Brown, R., Vikhamar Schuler, D., Bulygina, O., Derksen, C., Luojus, K., Mudr yk, L.: Arctic terrestrial snow cover. Snow, Water, Ice and Permafrost in the Arctic (SWIPA) 2017, Arctic Monitoring and Assessment Programme (AMAP), Oslo, Norway, 25-64, 2017.

Buixadé Farré, A., Stephenson, S. R., Chen, L., Czub, M., Dai, Y., Demchev, D.: Commercial Arctic shipping through the Northeast Passage: routes, reso urces, governance, technology, and infrastructure, Polar Geography, 37, 298 -324. https://doi.org/10.1080/1088937x.2014.965769, 2014.

Chen, J. L., Kang, S. C., Chen, C. S., You, Q. L., Du, W. T., Xu, M.: Chang es in sea ice and future accessibility along the Arctic Northeast Passage, Global Planet. Change, 195, 103319, https://doi.org/10.1016/j.gloplacha.2020. 103319, 2020.

Chen, S. Y., Cao, Y. F., Hui, F. M., and Cheng, X.: Observed spatial-temporal changes in the autumn navigability of the Arctic Northeast Route from 2 010 to 2017 (in Chinese), Chinese Sci. Bull., 64, 1515-1525, https://doi.or g/10.1360/N972018-01083, 2019.

Cohen, J., Zhang, X., Francis, J. A., Jung, T., Kwok, R., Overland, J.: Diverge nt consensuses on Arctic amplification influence on midlatitude severe wint er weather, Nat. Clim. Change, 10, 20-29, http://doi.org/10.1038/s41558-01 9-0662-y, 2020.

Comiso, J. C.: Large decadal decline of the Arctic multiyear ice cover, J. Cli mate, 25, 1176-1193, https://doi.org/10.1175/JCLI-D-11-00113.1, 2012.

Comiso, J. C., and Hall, D. K.: Climate trends in the Arctic as observed from 
space, Wires. Clim. Change, 5, 389-409, https://doi.org/10.1002/wcc.277, 20 14.

Cressey, D.: Arctic melt opens Northwest Passage, Nature, 449, 267-267. https:// doi.org/10.1038/449267b, 2007.

Gascard, J.-C., Riemann-Campe, K., Gerdes, R., Schyberg, H., Randriamampiani na, R., Karcher, M.: Future sea ice conditions and weather forecasts in the Arctic: Implications for Arctic shipping, Ambio, 46, 355-367, https://doi.or g/10.1007/s13280-017-0951-5, 2017.

Howell, S. E. L., and Yackel, J. J.: A vessel transit assessment of sea ice vari ability in the Western Arctic, 1969-2002: implications for ship navigation, Can. J. Remote Sens., 30, 205-215, https://doi.org/10.5589/m03-062, 2004.

IMO: Guidelines for ships operating in Arctic ice-covered waters, In: MSC/Circ.1056 and MEPC/Circ.399, 2002.

Jourdain, N. C., Mathiot, P., Merino, N., Durand, G., Le Sommer, J., Spence, P.: Ocean circulation and sea-ice thinning induced by melting ice shelves $\mathrm{i}$ $\mathrm{n}$ the Amundsen Sea, J. Geophys. Res-Oceans, 122, 2550-2573, https://doi. org/10.1002/2016jc012509, 2017.

Khon, V. C., Mokhov, I. I., Latif, M., Semenov, V. A., and Park, W.: Perspect ives of Northern Sea Route and Northwest Passage in the twenty-first cent ury, Climatic Change, 100, 757-768, https://doi.org/10.1007/s10584-009-9683 $-2,2009$.

Kwok, R.: Arctic sea ice thickness, volume, and multiyear ice coverage: losses and coupled variability (1958-2018), Environ. Res. Lett., 13, 105005, https: //doi.org/10.1088/1748-9326/aae3ec, 2018.

Lenton, T., Rockström, J., Gaffney, O., Rahmstorf, S., Richardson, K., Steffen, W.: Climate tipping points-too risky to bet against, Nature, 575, 592-595, https://doi.org/10.1038/d41586-019-03595-0, 2019.

Liu, X., Ma, L., Wang, J., Wang, Y., and Wang, L.: Navigable windows of th e Northwest Passage, Polar Sci., 13, 91-99, https://doi.org/10.1016/j.polar.20 17.02.001, 2017. 
Loomis, B. D., Rachlin, K. E., and Luthcke, S. B. Improved Earth oblateness r ate reveals increased ice sheet losses and mass - driven sea level rise. Geo phys. Res. Lett., 46, 6910-6917, https://doi.org/10.1029/2019g1082929, 201 9.

Melia, N., Haines, K., Hawkins, E., and Day, J. J.: Towards seasonal Arctic sh ipping route predictions. Environ. Res. Lett., 12, 084005, https://doi.org/10.1 088/1748-9326/aa7a60, 2017.

Meredith, M. P., Sommerkorn, M., Cassotta, S., Derksen, C., Ekaykin, A. A., Hollowed, A.: Chapter 3: Polar Regions. IPCC special report on the ocean and cryosphere in a changing climate, In press. https://report.ipcc.ch/srocc/ pdf/SROCC_FinalDraft_FullReport.pdf, 2019.

Notz, D.: Sea-ice extent and its trend provide limited metrics of model perfor mance, Cryosphere, 8, 229-243, https://doi.org/10.5194/tc-8-229-2014, 2014.

O’Neill, B. C., Kriegler, E., Riahi, K., Ebi, K. R., Hallegatte, S., Carter, T. R.: A new scenario framework for climate change research: the concept of $\mathrm{s}$ hared socioeconomic pathways, Climatic Change, 122, 387-400. https://doi. org/10.1007/s10584-013-0905-2, 2014.

Parkinson, C. L., Vinnikov, K. Y., and Cavalieri, D. J.: Evaluation of the simul ation of the annual cycle of Arctic and Antarctic sea ice coverages by 11 major global climate models, J. Geophys. Res., 111, https://doi.org/10.1029/ 2005jc003408, 2006.

Richter-Menge, J., Druckenmiller, M. L., and Jeffries, M.: Arctic Report Card 2019, https://www.arctic.noaa.gov/Report-Card, 2019.

Screen, J. A., and Simmonds, I.: Increasing fall-winter energy loss from the Ar ctic Ocean and its role in Arctic temperature amplification, Geophys. Res. Lett., 37, https://doi.org/10.1029/2010g1044136, 2010.

Shu, Q., Wang, Q., Song, Z. Y., Qiao, F. L., Zhao, J. C., Chun, M.: Assessm ent of sea ice extent in CMIP6 with comparison to observations and CMI P5. Geophys. Res. Lett., 47, e2020GL087965, https://doi.org/10.1029/2020G L087965, 2020. 
432 SIMIP Community: Arctic sea ice in CMIP6, Geophys. Res. Lett., 47, e2019G 433 L086749, https://doi.org/10.1029/2019GL086749, 2020.

434 Smith, L. C., and Stephenson, S. R.: New Trans-Arctic shipping routes navigab 435 le by midcentury, P. Nati. Acad. Sci. USA, 110, E1191-E1195, https://doi. org/10.1073/pnas.1214212110, 2013.

437 Stephenson, S. R., Smith, L. C., Brigham, L. W., and Agnew, J. A.: Projected

438 21st-century changes to Arctic marine access, Climatic Change, 118, 885-8 99, https://doi.org/10.1007/s10584-012-0685-0, 2013.

440 Stroeve, J., Barrett, A., Serreze, M., and Schweiger, A.: Using records from su bmarine, aircraft and satellite to evaluate climate model simulations of Arc tic sea ice thickness, Cryosphere, 8, 1839-1854, https://doi.org/10.5194/tc-81839-2014, 2014.

444 Transport Canada: Arctic Ice Regime Shipping System (AIRSS) Standards (Otta wa), Transport Canada, Ottawa, https://tc.canada.ca/en/marine-transportation/a rcticshipping/arctic-ice-regime-shipping-system-airss, 1998. 